\title{
Management of internal carotid artery near-occlusion: the need for updated evidence
}

\author{
Constantine N. Antonopoulos ${ }^{1}$, Alexandros Giosdekos ${ }^{1}$, Spyridon N. Mylonas ${ }^{1,2}$, Christos D. Liapis ${ }^{1}$ \\ ${ }^{1}$ Athens Vascular Research Center, Athens, Greece; ${ }^{2}$ Department of Vascular and Endovascular Surgery, University of Cologne, Cologne, Germany \\ Contributions: (I) Conception and design: All authors; (II) Administrative support: CD Liapis; (III) Provision of study materials or patients: None; \\ (IV) Collection and assembly of data: CN Antonopoulos, A Giosdekos; (V) Data analysis and interpretation: All authors; (VI) Manuscript writing: All \\ authors; (VII) Final approval of manuscript: All authors. \\ Correspondence to: Christos D. Liapis, MD, FACS, FRCS, FEBVS. Professor (em) of Vascular Surgery, Athens Vascular Research Center, Athens, \\ Greece. Email: liapis@med.uoa.gr.
}

\begin{abstract}
Near occlusion of internal carotid artery (ICA) is a rare and easily misdiagnosed condition and the decision for revascularisation still remains controversial. We conducted an updated meta-analysis in order to investigate outcomes after carotid endarterectomy (CEA), carotid artery stenting (CAS) or best medical treatment (BMT) in patients with near-occlusion of the ICA. We also aimed to investigate the role of time as a potential moderator of the near-ICA occlusion-stroke rate association. A multiple electronic health database search on articles published up to November 2019 was performed. The pooled stroke rate after CEA, CAS and BMT were calculated. We also investigated transient ischemic attack (TIA), strokerelated death, myocardial infarction (MI), any cause of death and ICA restenosis crude rates (\%). A total of 33 articles were finally deemed eligible. The pooled stroke rate was $1.52 \%$ [95\% confidence interval (CI): 0.09-4.02\%] after CEA, 1.80\% (95\% CI: 0.61-3.40\%) after CAS and 8.39\% (95\% CI: 3.39-14.80\%) after BMT. Out of 896 CEA patients, we recorded 22 TIAs (2.5\%), 33 all-cause deaths (3.7\%), 5 stroke-related deaths $(0.6 \%)$ and 6 MIs $(0.7 \%)$. Concerning outcomes after 603 CAS patients, we recorded 7 TIAs (1.2\%), 56 all-cause deaths (9.3\%), 4 stroke-related deaths (0.7\%) and 22 MIs (3.6\%). Among 263 patients who were treated with BMT, we found 16 TIAs (6.1\%), 10 all-cause deaths (3.8\%), no stroke-related death, and no MI. Crude restenosis rate during follow-up was 9.0\% (54/601) for CEA and 4.1\% (24/592) for CAS patients. No significant effect of publication year upon stroke rate after CEA was recorded. However, there was a significant reversed association between pooled stroke rate after $\mathrm{CAS}$ and publication year $(\mathrm{P}=0.05)$. A statistically significant reversed association between pooled stroke rate after BMT and publication year was also recorded $(\mathrm{P}<0.01)$. The results of this updated meta-analysis revealed high stroke rate for patients with near-occlusion of ICA who treated only with BMT, while intervention seemed to be safe and effective. A downward trend in the stroke rates over time after CAS and BMT was also discovered. These highlight that patients with near-occlusion of ICA should be included and investigated in future studies.
\end{abstract}

Keywords: Carotid artery; near occlusion; meta-analysis; string sign; stroke

Submitted Dec 19, 2019. Accepted for publication Mar 11, 2020.

doi: $10.21037 /$ atm.2020.03.148

View this article at: http://dx.doi.org/10.21037/atm.2020.03.148 


\section{Background}

Stroke is the fifth leading cause of death and a major cause of serious long-term disability for adults (1). The degree of internal carotid artery (ICA) stenosis is one of the most important factors, affecting the decision whether subsequent intervention is warranted, as it is directly linked to the risk of stroke. More specifically, an increased degree of ICA stenosis has been associated with a higher risk for ipsilateral stroke, based on the findings of the North American Symptomatic Carotid Endarterectomy Trial (NASCET) $(2,3)$. This study showed a high stroke incidence in medically treated patients, while carotid artery endarterectomy (CEA) was proved as beneficial. However, a later sub-analysis of this study, yielded a 1-year stroke rate of $11 \%$ in the patients with almost complete occlusion of the ICA, contrary to $35 \%$ in the patients with less than 94\% ICA stenosis (3), making the indication for surgical intervention in the first population rather unclear. Further analysis of the three most important randomized controlled trials (RCTs) comparing CEA with best medical treatment (BMT), namely NASCET, European Carotid Surgery Trial (ECST) and the Symptomatic Veterans Affairs Co-operative Study (SVACS) Trial, showed that the benefit conferred by CEA increased with increasing stenosis severity, with the exclusion of "near-occlusion". More specifically, patients with chronic near occlusion (defined as a $95-99 \%$ stenosis with distal ICA collapse or a narrow calibre lumen with "trickle flow") gained no obvious benefit from CEA $(4,5)$.

Since the original publication of the three RCTs, many other studies have focused on the optimal treatment of patients with near ICA occlusion in the form of CEA, carotid artery stenting (CAS) or BMT. A recent European Society for Vascular Surgery (ESVS) Guidelines document (6) on the management of carotid artery disease recommended conservative treatment in symptomatic patients with a chronic ICA near-occlusion, unless associated with recurrent ipsilateral symptoms despite optimal medical therapy. However, this recommendation did not take into consideration the "real-world", non-randomized studies, and it was based on rather outdated data. Furthermore, a recent individual patient meta-analysis (7), concluded that BMT alone is not superior to CEA or CAS with respect to 30-day or 1-year stroke or death prevention in patients with near ICA occlusion. Similarly, a previous review by our team (8), which included five articles on BMT and CEA, eight articles on CEA, and eleven articles on CAS published up to December 2014 provided with evidence that an intervention is probably indicated for patients with near-total ICA occlusion. However, during the last 5 years, many more studies were added to the literature, thus making an update pertinent.

The aim of this study was to update our early systematic review in order to investigate outcomes after CEA, CAS or BMT in patients with near-occlusion of the ICA. We also aimed to investigate the role of time as a potential moderator of the near-ICA occlusion-stroke rate association.

\section{Methods}

We conducted a systematic review and meta-analysis according the published recommendations of the Metaanalysis of Observational Studies in Epidemiology (MOOSE) group (9). Our literature review included the electronic health databases of Medline, Ovid and the Cochrane Database of Systematic Reviews. We focused on articles evaluating treatment options, including BMT, CEA or CAS for patients with near total ICA occlusion. For that reason, we used MeSH (medical subject heading) terminology with keywords: "carotid", "critical stenosis", "internal carotid artery", "near total occlusion", "subocclusion”, "pre-occlusion", "pseudo-occlusion”, "string sign", "slim sign". Articles describing ligation of the ICA due to near total ICA occlusion were excluded. Two independent reviewers (CN Antonopoulos, A Giosdekos) performed the literature review and the data extraction of articles published in English up to November 2019. From all eligible articles, along with baseline characteristics, we focused on outcomes after application of the treatment (CEA, CAS or BMT), including, transient ischemic attack (TIA), stroke, stroke-related death, myocardial infarction (MI), any cause of death and ICA restenosis. After extraction of the number of patients with outcome events (used as numerator) and the total number of patients included in each study (used as denominator), we presented outcome rates for each study as crude rates (\% percentage). For the outcome of "stroke" we also calculated crude outcome rate with $95 \%$ confidence intervals (95\% CIs). The corresponding rate was thereafter transformed into quantities according to the Freeman-Tukey variant of the arcsine square root transformed proportion (10). The pooled effect estimate of stroke, was calculated as the backtransformation of the weighted mean of the transformed proportion, using inverse arcsine variance weights for the fixed effects model or DerSimonian-Laird weights in case of 


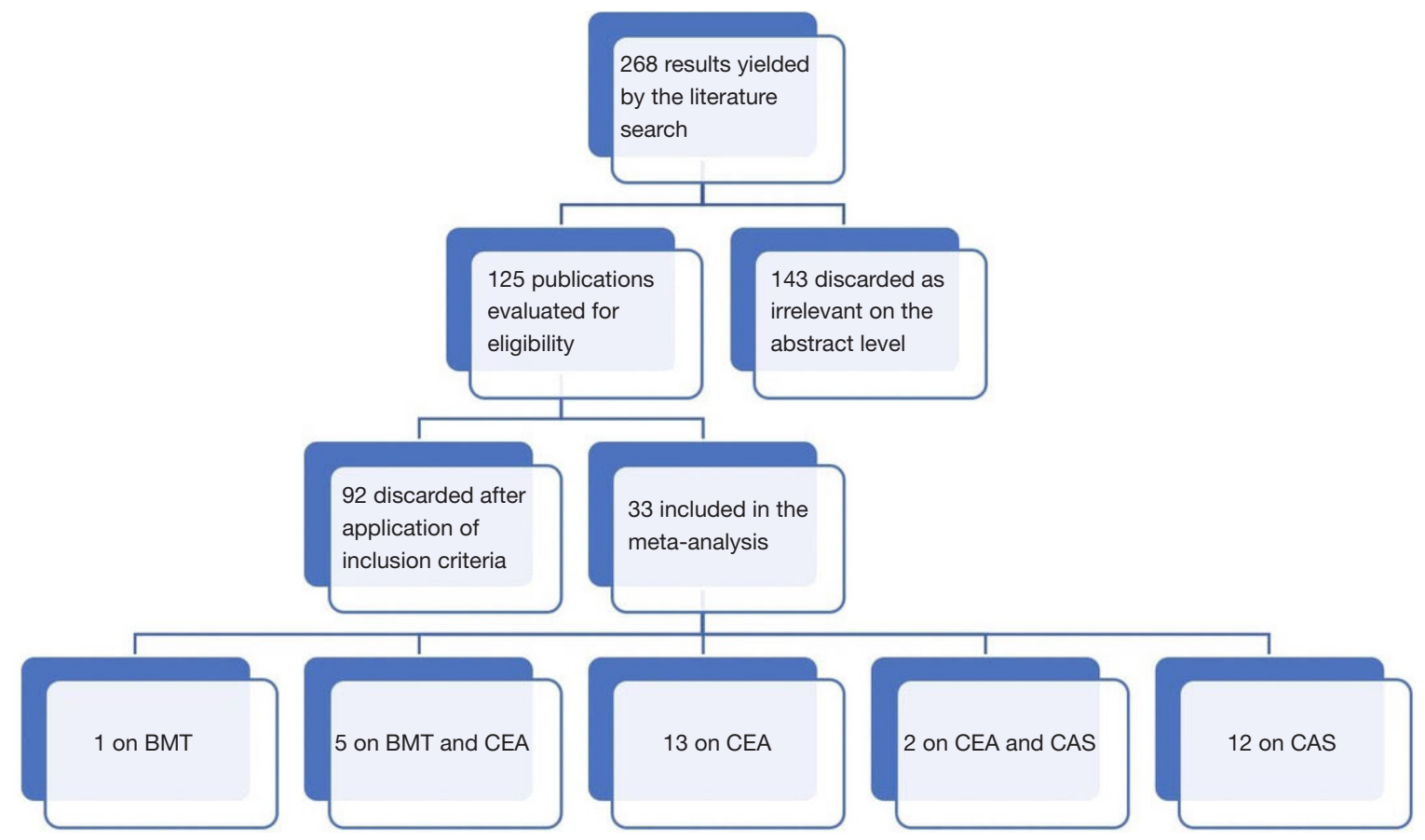

Figure 1 Flow chart. BMT, best medical treatment; CEA, carotid endarterectomy; CAS, carotid artery stenting.

random effects model (11). We assessed the heterogeneity among studies with the Cochran Q score (reported as $\mathrm{I}^{2}$ ), while publication bias was assessed with Egger's regression test and funnel plot. Thereafter, we performed a metaregression analysis in order to investigate the role of publication year as a potential modifier upon the effect estimate of stroke, with the aim to explore the effect of time by means of improvements in each one of the treatment arms upon stroke rate. The meta-analysis was conducted using Stata 14.2 (StataCorp, College Station, TX, USA).

\section{Results}

After an initial search in the literature, we identified 268 potentially eligible studies. Review of the titles and abstracts evidenced that 143 were irrelevant. After applying exclusion criteria, 92 studies were excluded and finally 33 articles participated in the meta-analysis. More specifically, the literature review revealed 13 articles on CEA (12-24), 12 articles on CAS (25-36), 5 studies on BMT and CEA (37-41), 2 studies on CEA and CAS $(42,43)$ and 1 study on BMT (44) (Figure 1: flow chart). The demographic characteristics of the 33 eligible studies included in our study are presented in Tables 1,2. Among the patients who received CAS almost $76 \%$ were symptomatic, the mean age was 69 years, embolic filter devices were used in $75.2 \%$ of the cases and the mean follow up was 20.5 months. Among the patients who were treated with CEA, about $80 \%$ were symptomatic, the mean age was 65.8 years, patch applied in $34 \%$ of the cases and the mean follow up was 26.2 months. It should be mentioned that in 7 patients $(18,37,38)$ the ICA was ligated and thus they were excluded from the further analysis. Out of 896 CEA patients, we recorded 22 TIAs (2.5\%), 33 all-cause deaths (3.7\%), 5 stroke-related deaths $(0.6 \%)$ and 6 MIs (0.7\%). Concerning outcomes after 603 CAS patients, the respective number of events and crude rates were 7 TIAs (1.2\%), 56 all-cause deaths (9.3\%), 4 stroke-related deaths $(0.7 \%)$ and 22 MIs (3.6\%). Among 263 patients who were treated solely with BMT, the events and crude rates were 16 TIAs (6.1\%), 10 all-cause deaths (3.8\%), no stroke-related death, and no MI, although only one study reported on the last outcome. Crude restenosis rate during follow-up was 9.0\% (54/601) for CEA and 4.1\% (24/592) for CAS patients.

The pooled stroke rate after CEA was $1.52 \%$ (95\% CI: $0.09-4.02 \%$; Figure 2), while the respective rate for CAS was $1.80 \%$ (95\% CI: $0.61-3.40 \%$; Figure 3). Evaluation of the eligible studies reporting stroke rates after BMT only, revealed a pooled stroke rate of $8.39 \%$ (95\% CI: 3.39 $14.80 \%$; Figure 4). No significant effect of publication year 
Table 1 Eligible studies on carotid endarterectomy (CEA) and best medical treatment (BMT)

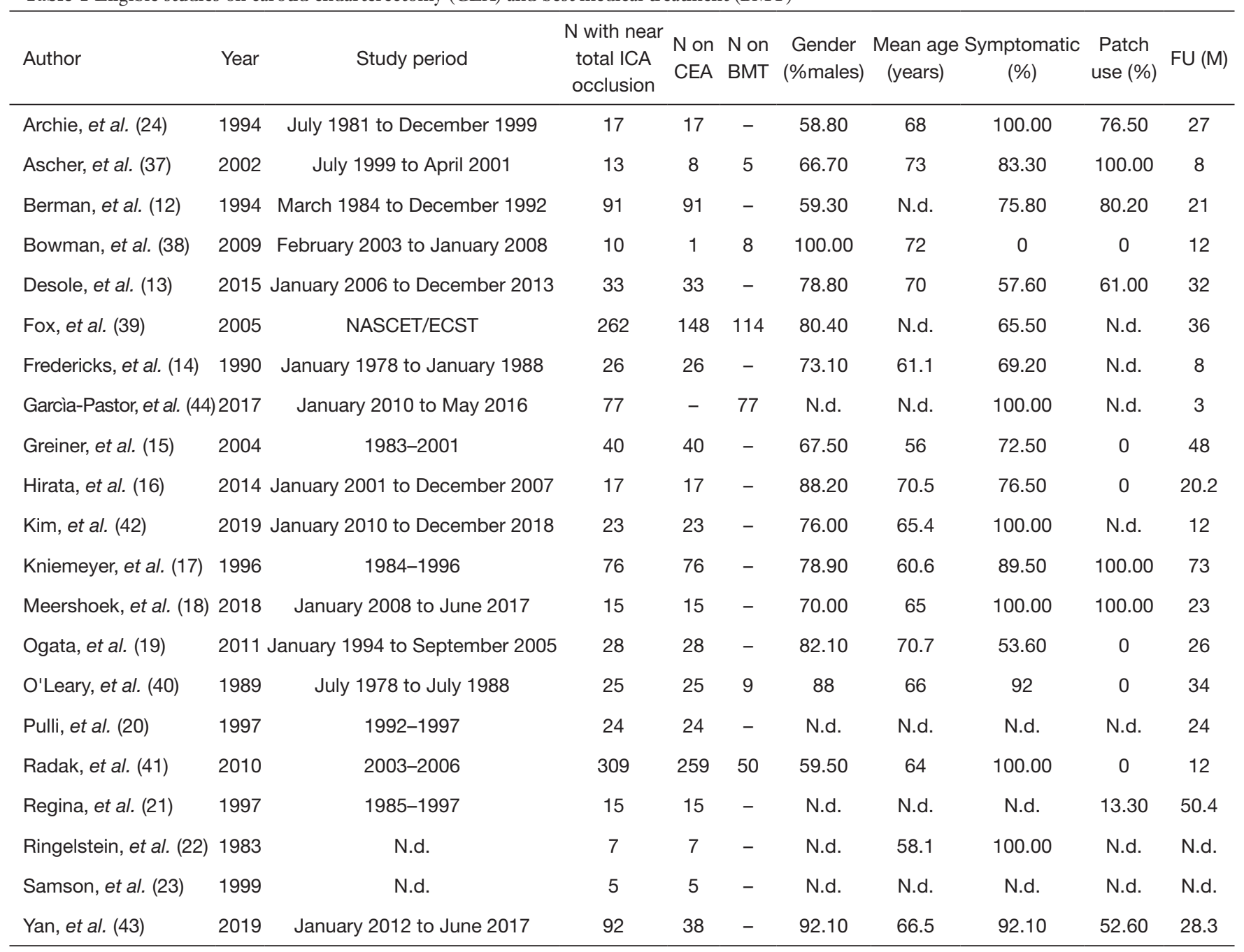

$\mathrm{N}$, total number of patients; CEA, carotid endarterectomy; BMT, best medical treatment; FU, follow-up; N.d., not defined; M, months; NASCET, North American Symptomatic Carotid Endarterectomy Trial; ECST, European Carotid Surgery Trial.

upon stroke rate after CEA was recorded ( $>0.05$; Figure 5). However, meta-regression analysis showed a significant reversed association between pooled stroke rate after CAS and publication year ( $\mathrm{P}=0.05$; Figure 6). A statistically significant and reversed association between pooled stroke rate after BMT and publication year was also recorded $(\mathrm{P}<0.01$; Figure 7).

\section{Discussion}

Our systematic review and meta-analysis focused on patients with near-occlusion of the ICA. We analyzed 33 eligible studies, including 896 CEA, 603 CAS and 263 BMT patients. We estimated a pooled rate of $1.5 \%$ for
CEA, $1.8 \%$ for CAS and $8.4 \%$ for BMT, highlighting a higher stroke rate for patients who were not offered any carotid intervention. We also found a significant reversed association between pooled stroke rate after CAS or BMT with publication year. The latter may underline the potential improvements in carotid stenting technique, along with optimization and better adherence to medical treatment over time for the subgroup of patients with nearocclusion of the ICA.

The term pseudo occlusion of the ICA was first used by Lippman et al. (45), in 1970 and was defined as the presence of a very tight stenosis of the ICA with an extremely narrow residual lumen and a collapsed distal portion induced by hypoperfusion. Angiographically, it resembles a thin 
Table 2 Eligible studies on carotid artery stenting (CAS)

\begin{tabular}{|c|c|c|c|c|c|c|c|c|c|}
\hline Authors & Year & Study period & $\mathrm{N}$ & $\begin{array}{c}\text { Gender (\% } \\
\text { males) }\end{array}$ & $\begin{array}{l}\text { Mean age } \\
\text { (years) }\end{array}$ & $\begin{array}{c}\text { Symptomatic } \\
(\%)\end{array}$ & $\begin{array}{l}\text { EPD use } \\
(\%)\end{array}$ & $\begin{array}{c}\text { Pre-dilatation } \\
(\%)\end{array}$ & FU (M) \\
\hline Akkan, et al. (25) & 2018 & 2004-2014 & 182 & 72.50 & 70.2 & 56.00 & 60.50 & 100.00 & 64 \\
\hline Choi, et al. (27) & 2010 & 2005-2010 & 48 & 85.40 & 69 & 100.00 & N.d. & N.d. & 6 \\
\hline Nikas, et al. (29) & 2010 & October 2006 to August 2007 & 25 & 84.00 & 70.9 & 80.00 & 96.00 & 68.00 & 12 \\
\hline $\begin{array}{l}\text { Ruiz-Salmeron, } \\
\text { et al. (32) }\end{array}$ & 2013 & January 2008 to March 2012 & 54 & 83.30 & 67 & 74.10 & 53.70 & N.d. & 1 \\
\hline Terada, et al. (36) & 2006 & 1991-2003 & 20 & 100.00 & 69.1 & 85.00 & 95.00 & 100.00 & 25 \\
\hline Razuk, et al. (31) & 2010 & N.d. & 13 & N.d. & N.d. & 61.50 & 100.00 & 76.90 & 12 \\
\hline Sakamoto, et al. (33) & 2013 & April 2008 to September 2012 & 14 & 100.00 & 75.4 & 71.40 & 64.30 & N.d. & 17 \\
\hline Oka, et al. (30) & 2013 & July 2006 to June 2012 & 15 & 93.30 & 70.6 & 66.70 & 100.00 & N.d. & 38 \\
\hline Yan, et al. (43) & 2019 & January 2012 to June 2017 & 54 & 92.60 & 68.1 & 96.30 & 100.00 & 6.50 & 28.3 \\
\hline
\end{tabular}

$\mathrm{N}$, total number of patients; EPD, embolic protection device; FU, follow-up; N.d., not defined; M, months.

string and several terms have been used so far to describe this entity: "string sign", "pseudoocclusion", "incomplete occlusion", "near occlusion", "subtotal occlusion", "slim sign", "small distal ICA" or "poststenotic narrowing". Four angiographic criteria were suggested by Fox et al. (39) to define near total ICA occlusion: (I) reduction in ICA diameter compared with the ipsilateral external carotid artery (ECA), (II) obviously reduced diameter of the ICA compared with the opposite ICA, (III) intracranial collaterals seen as a cross-filling of contralateral vessels or ipsilateral contrast dilution and (IV) delayed cranial arrival of ICA contrast compared with that of the ECA.

Near occlusion of the ICA is a relative rare condition with incidence varying from $0.5 \%$ to $2 \%$ (46). Ultimately, total ICA occlusion will occur in $40 \%$ of the patients within 12 months (40) and cerebrovascular or cardiac events are more frequent in patients with near-total ICA occlusion, compared with patients with carotid artery stenosis (20). Although CEA is the gold standard for significant symptomatic carotid artery stenosis, the treatment management of patients with near ICA occlusion remains controversial. Furthermore, a near occlusion of the ICA can be easily misdiagnosed and misclassified as complete ICA occlusion. Current ESVS guidelines (6) recommend BMT for this specific group of patients. This recommendation was based on evidence from post hoc analyses of the North American Symptomatic Endarterectomy Trial (NASCET), the ECST and the Veterans Affairs trial, which reported that the risk of stroke in patients with near occlusion of ICA was low with medical treatment and there was no surgical benefit (4). However, these trials were performed in the 1990s and this recommendation is based on level III and class C evidence. Furthermore, SVS Guidelines (47) do not discriminate treatment between high grade and near occlusion ICA patients. What is more, some patients with near-total ICA occlusion may progress to total occlusion with BMT alone and this may hamper the hemodynamic reservoir of the brain vascular bed, which might be especially important in case of contralateral ICA occlusion. Our study indicated lower stroke rates after CEA and CAS, compared to medical therapy. This is in line with a recent individual patient meta-analysis (7). Although it finally 


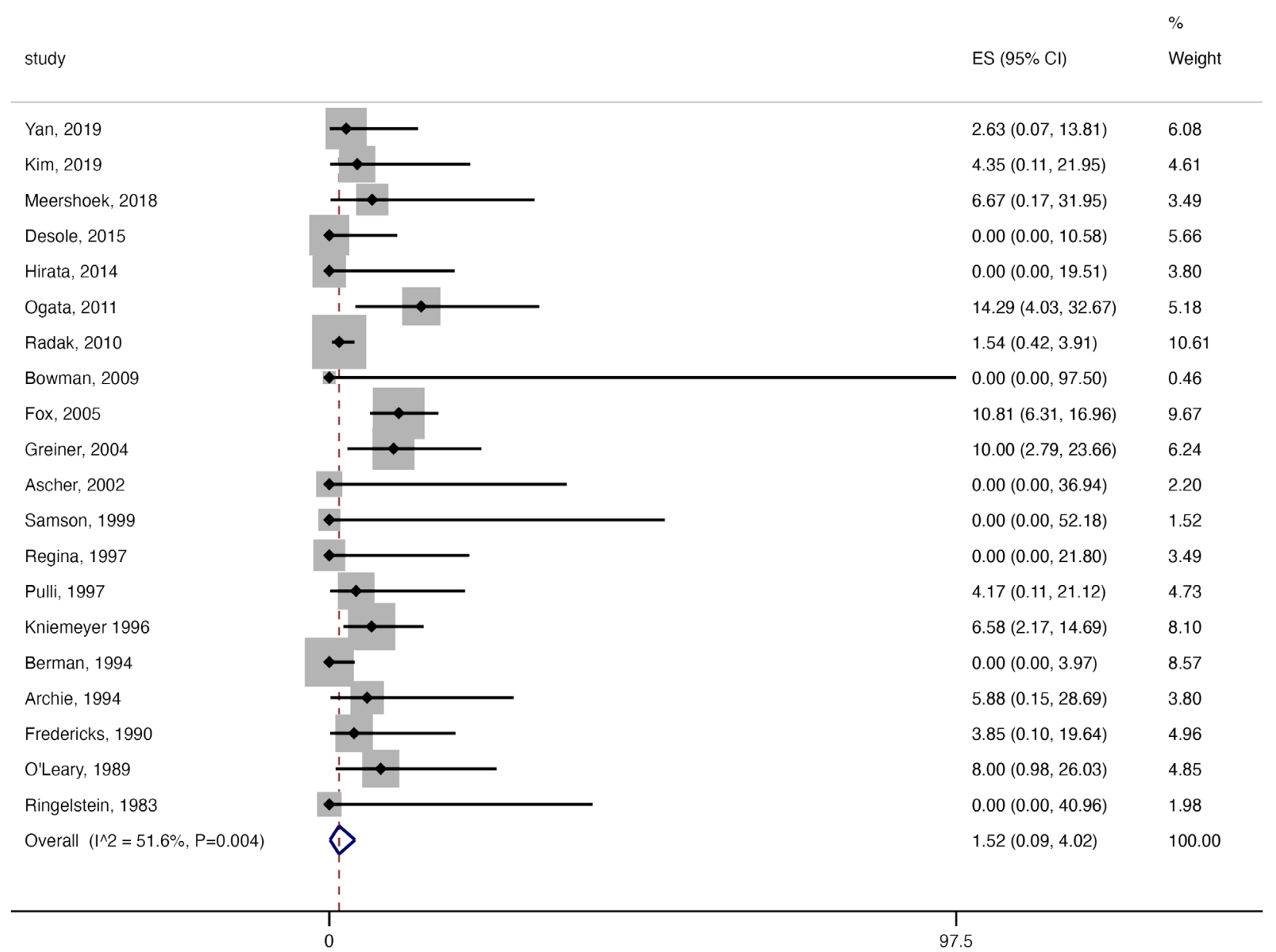

Figure 2 Forest plot presenting the meta-analysis of stroke rates after carotid endarterectomy (CEA). Event rates in the individual studies are presented as squares with $95 \%$ confidence intervals (CIs) presented as extending lines. The pooled event rate with its $95 \%$ CI is depicted as a diamond. ES, effect estimate.

included data only from 11 studies, after exclusion of 21 eligible studies due to unavailable data, this study concluded that BMT alone is not superior to CEA or CAS with respect to 30-day or 1-year stroke or death prevention in patients with near ICA occlusion, which was also supported by others (48-50). Furthermore, the authors of two metaanalyses $(7,51)$ also underlined that consideration should made to include patients with near occlusion in future RCTs. As a result, it is obvious that no consensus on the management of this group of patients has yet been reached and there is need for updated evidence.

The result of our new updated meta-analysis depicts that the stroke rates after CEA have remained relatively stable. However, stroke rates after CAS have decreased, which may correspond to improvements in CAS material, technique and learning curve. Interestingly, Smout et al. (52), reported that in high volume CAS units, it may take almost 2 years before the stroke/death rates fall below an arbitrary $5 \%$ threshold. As a result, currently, near occlusion of the ICA can be successfully treated by endovascular procedures by an experienced team, although wire manipulation in ICA with near occlusion may still increase the risk for ipsilateral stroke. On the other hand, stroke rates after BMT have also substantially decreased over time, which is mainly attributed to great improvements in medical therapy. Apparently, BMT has improved significantly over the past 25 years, due to new antiplatelet and anticoagulation therapy and a high-intensity statin therapy. Taken as a whole, the current optimum medical therapy includes smoking cessation, blood pressure control, diabetes mellitus control, antiplatelet 


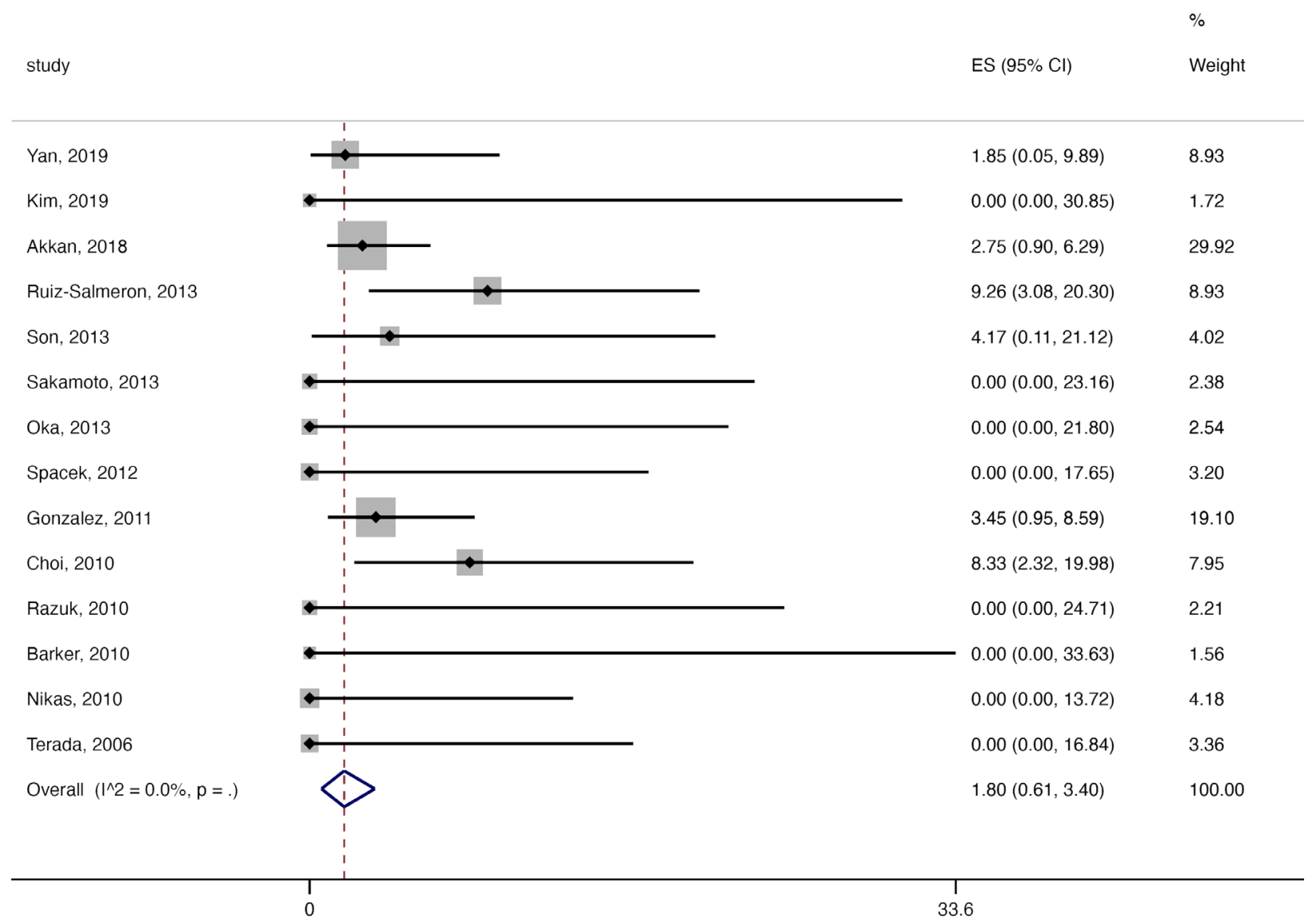

Figure 3 Forest plot presenting the meta-analysis of stroke rates after carotid artery stenting (CAS). Event rates in the individual studies are presented as squares with $95 \%$ confidence intervals (CIs) presented as extending lines. The pooled event rate with its $95 \%$ CI is depicted as a diamond. ES, effect estimate.

therapy and aggressive statin medication. Lifestyle changes are also very important such as a balanced diet and moderate exercise.

In addition, we need to highlight the difference between the near occlusion of the ICA with or without collapse of the distal ICA. Initially, near occlusion was defined in association with full collapse of the distal ICA, which is often referred as a string sign. Near occlusion with full ICA collapse is well-known with a threadlike lumen while without collapse refers to a smaller calibre of the vessel than the original size but without having this characteristic threadlike appearance (46). Unfortunately, many studies have not separated these two entities as it seems that the possibility of near occlusion without full collapse has not been fully recognised. Johansson et al. $(46,53)$ detected that patients with a symptomatic ICA near occlusion with full collapse had a very high risk of ipsilateral ischemic stroke recurrence, whereas those without full collapse had a low risk. According to this study, the 90-day risk of recurrent stroke was $0 \%$ for patients with near-occlusion without full collapse but $43 \%$ for patients with nearocclusion with full collapse (53). This result challenges the current guidelines, which suggest BMT without highlighting the difference between near occlusion with or without collapse.

Our study has some limitations, which should be reported. Firstly, differences in design among the eligible studies make heterogeneity among studies an inherent limitation. Secondly, the retrospective nature of the eligible studies, along with the lack of control group should be acknowledged. Diversity in follow-up period and definitions of near total occlusion might have also been reflected upon the pooled effect estimates. Discrimination of data between symptomatic and asymptomatic patients along with near ICA occlusion with and without full collapse was not feasible and as a result no further subgroup analysis was possible. 


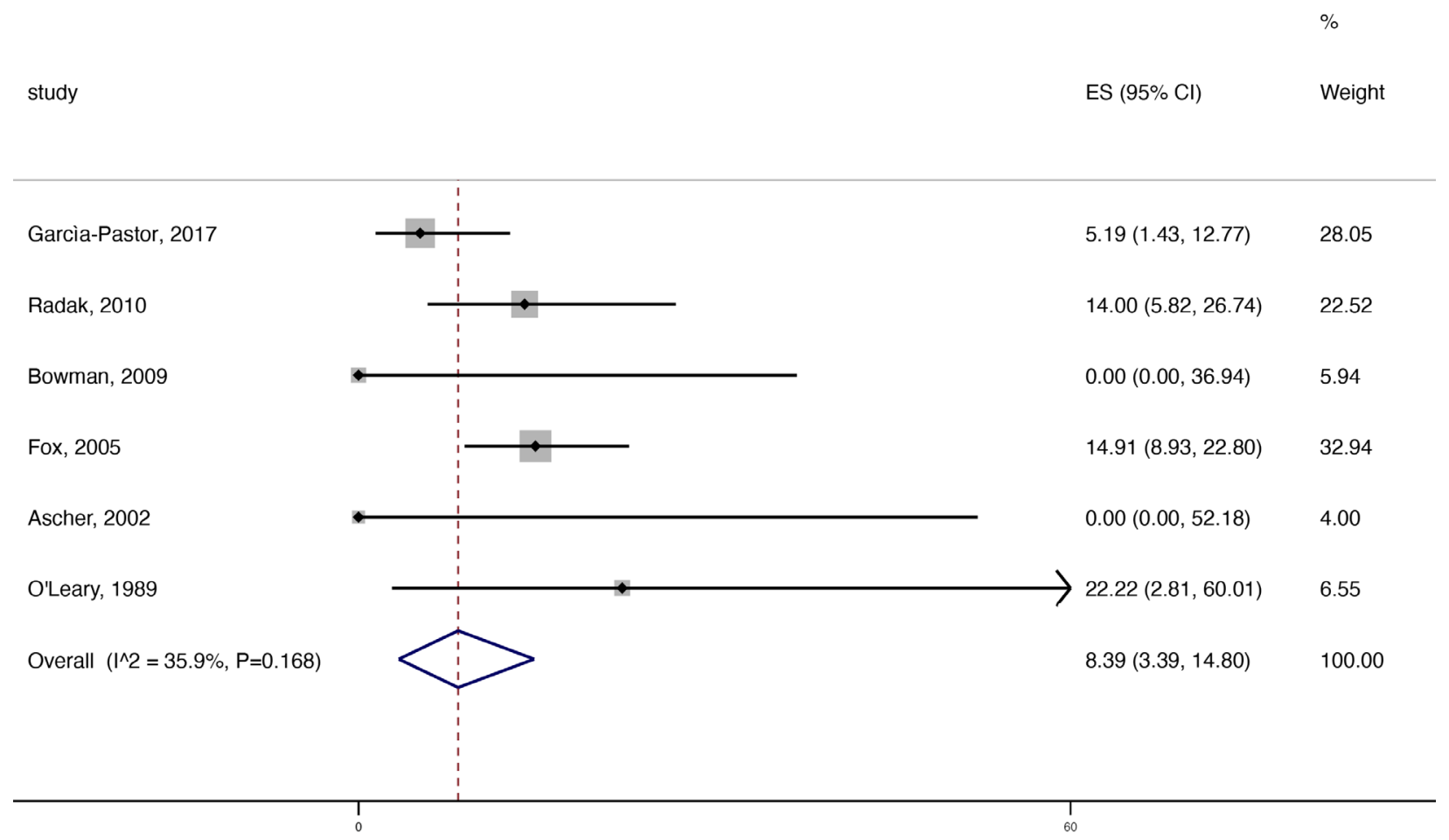

Figure 4 Forest plot presenting the meta-analysis of stroke rates after best medical treatment (BMT). Event rates in the individual studies are presented as squares with $95 \%$ confidence intervals (CIs) presented as extending lines. The pooled event rate with its $95 \%$ CI is depicted as a diamond. ES, effect estimate.

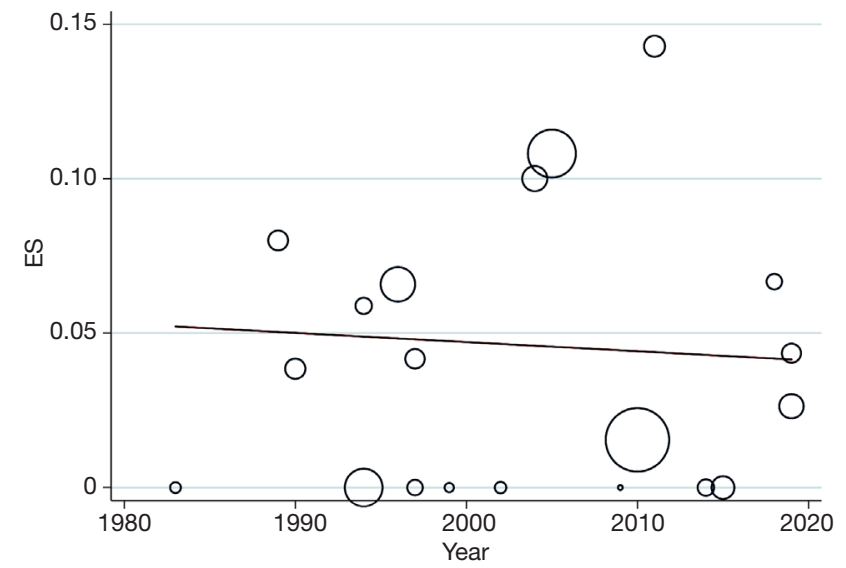

Figure 5 Forest plot presenting the meta-regression of stroke rates after carotid endarterectomy (CEA) with publication year.

\section{Conclusions}

Near-occlusion of ICA is a rare and easily misdiagnosed condition and the treatment strategy still remains controversial. This updated meta-analysis depicts the high stroke rate for patients who treated only with BMT and

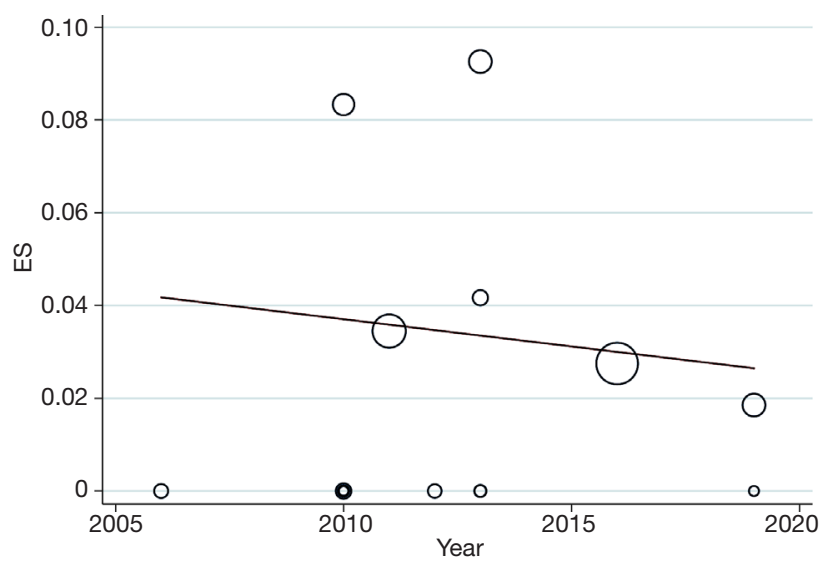

Figure 6 Forest plot presenting the meta-regression of stroke rates after carotid artery stenting (CAS) with publication year.

reinforce the opinion that both CEA and CAS seem to be safe and appropriate treatment for this group of patients. A downward trend in the stroke rates over time after CAS and BMT was also discovered. Patients with near-occlusion of ICA, with or without full collapse, need to be included and 


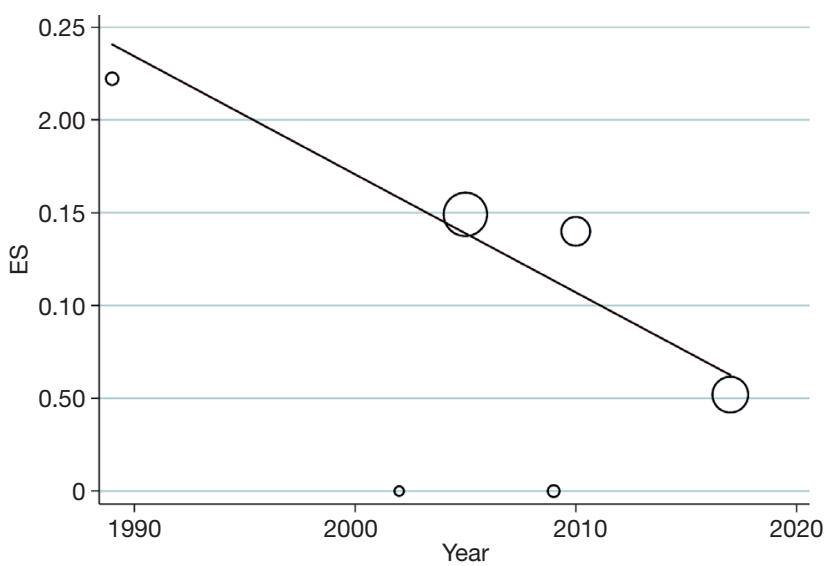

Figure 7 Forest plot presenting the meta-regression of stroke rates after best medical treatment (BMT) with publication year.

investigated in future RCTs.

\section{Acknowledgments}

Funding: None.

\section{Footnote}

Provenance and Peer Review: This article was commissioned by the Guest Editor (Dr. Kosmas I. Paraskevas) for the series "Carotid Artery Stenosis and Stroke: Prevention and Treatment Part I" published in Annals of Translational Medicine. The article was sent for external peer review organized by the Guest Editor and the editorial office.

Conflicts of Interest: All authors have completed the ICMJE uniform disclosure form (available at http://dx.doi. org/10.21037/atm.2020.03.148). The series "Carotid Artery Stenosis and Stroke: Prevention and Treatment Part I" was commissioned by the editorial office without any funding or sponsorship. The authors have no other conflicts of interest to declare.

Ethical Statement: The authors are accountable for all aspects of the work in ensuring that questions related to the accuracy or integrity of any part of the work are appropriately investigated and resolved.

Open Access Statement: This is an Open Access article distributed in accordance with the Creative Commons Attribution-NonCommercial-NoDerivs 4.0 International
License (CC BY-NC-ND 4.0), which permits the noncommercial replication and distribution of the article with the strict proviso that no changes or edits are made and the original work is properly cited (including links to both the formal publication through the relevant DOI and the license). See: https://creativecommons.org/licenses/by-nc-nd/4.0/.

\section{References}

1. Writing Group Members, Mozaffarian D, Benjamin EJ, et al. Heart Disease and Stroke Statistics-2016 Update: A Report From the American Heart Association. Circulation 2016;133:e38-360. Erratum in: Correction. [Circulation. 2016].

2. Clinical alert: benefit of carotid endarterectomy for patients with high-grade stenosis of the internal carotid artery. National Institute of Neurological Disorders and Stroke Stroke and Trauma Division. North American Symptomatic Carotid Endarterectomy Trial (NASCET) investigators. Stroke 1991;22:816-7.

3. Morgenstern LB, Fox AJ, Sharpe BL, et al. The risks and benefits of carotid endarterectomy in patients with near occlusion of the carotid artery. North American Symptomatic Carotid Endarterectomy Trial (NASCET) Group. Neurology 1997;48:911-5.

4. Rothwell PM, Eliasziw M, Gutnikov SA, et al. Analysis of pooled data from the randomised controlled trials of endarterectomy for symptomatic carotid stenosis. Lancet 2003;361:107-16.

5. Rothwell PM, Eliasziw M, Gutnikov SA, et al. Endarterectomy for symptomatic carotid stenosis in relation to clinical subgroups and timing of surgery. Lancet 2004:363:915-24.

6. Aboyans V, Ricco JB, Bartelink MEL, et al. Editor's Choice - 2017 ESC Guidelines on the Diagnosis and Treatment of Peripheral Arterial Diseases, in collaboration with the European Society for Vascular Surgery (ESVS). Eur J Vasc Endovasc Surg 2018;55:305-68.

7. Meershoek AJA, de Vries EE, Veen D, et al. Meta-analysis of the outcomes of treatment of internal carotid artery near occlusion. Br J Surg 2019;106:665-71.

8. Mylonas SN, Antonopoulos CN, Moulakakis KG, et al. Management of Patients with Internal Carotid Artery Near-total Occlusion: An Updated Meta-analysis. Ann Vasc Surg 2015;29:1664-72.

9. Stroup DF, Berlin JA, Morton SC, et al. Meta-analysis of observational studies in epidemiology: a proposal for reporting. Meta-analysis Of Observational Studies in 
Epidemiology (MOOSE) group. JAMA 2000;283:2008-12.

10. Stuart A, Ord K. Kendall's advanced theory of statistics. London: Edward Arnold, 1994.

11. DerSimonian R, Laird N. Meta-analysis in clinical trials revisited. Contemp Clin Trials 2015;45:139-45.

12. Berman SS, Bernhard VM, Erly WK, et al. Critical carotid artery stenosis: diagnosis, timing of surgery, and outcome. J Vasc Surg 1994;20:499-508; discussion 508-10.

13. Desole A, Campanile F, Tosato F, et al. Surgical treatment for pseudo-occlusion of the internal carotid artery. Interact Cardiovasc Thorac Surg 2015;20:636-40.

14. Fredericks RK, Thomas TD, Lefkowitz DS, et al. Implications of the angiographic string sign in carotid atherosclerosis. Stroke 1990;21:476-9.

15. Greiner C, Wassmann H, Palkovic S, et al. Revascularization procedures in internal carotid artery pseudo-occlusion. Acta Neurochir (Wien) 2004;146:23743; discussion 243.

16. Hirata Y, Sakata N, Tsuchimochi H, et al. Carotid Endarterectomy for Pseudo-occlusion of the Cervical Internal Carotid Artery. Acta Neurochir Suppl 2014;119:91-6.

17. Kniemeyer HW, Aulich A, Schlachetzki F, et al. Pseudoand segmental occlusion of the internal carotid artery: a new classification, surgical treatment and results. Eur J Vasc Endovasc Surg 1996;12:310-20.

18. Meershoek AJA, Vonken EPA, Nederkoorn PJ, et al. Carotid endarterectomy in patients with recurrent symptoms associated with an ipsilateral carotid artery near occlusion with full collapse. J Neurol 2018;265:1900-5.

19. Ogata T, Yasaka M, Kanazawa Y, et al. Outcomes associated with carotid pseudo-occlusion. Cerebrovasc Dis 2011;31:494-8.

20. Pulli R, Frosini P, Gatti M, et al. Internal carotid pseudoocclusion: early and late results. J Cardiovasc Surg (Torino) 1997;38:15-20.

21. Regina G, Testini M, Fullone M, et al. Pseudo-occlusion of the internal carotid artery: report of 15 cases and review of the literature. Int Angiol 1997;16:147-50.

22. Ringelstein EB, Berg-Dammer E, Zeumer H. The socalled atheromatous pseudoocclusion of the internal carotid artery. A diagnostic and therapeutical challenge. Neuroradiology 1983;25:147-55.

23. Samson RH, Showalter DP, Yunis JP, et al. Color flow scan diagnosis of the carotid string may prevent unnecessary surgery. Cardiovasc Surg 1999;7:236-41.

24. Archie JP Jr. Carotid endarterectomy when the distal internal carotid artery is small or poorly visualized. J Vasc
Surg 1994;19:23-30; discussion 30-1.

25. Akkan K, Ilgit E, Onal B, et al. Endovascular Treatment for Near Occlusion of the Internal Carotid Artery: 30-Day Outcome and Long-Term Follow-Up. Clin Neuroradiol 2018;28:245-52.

26. Barker CM, Gomez J, Grotta JC, et al. Feasibility of carotid artery stenting in patients with angiographic string sign. Catheter Cardiovasc Interv 2010;75:1104-9.

27. Choi BS, Park JW, Shin JE, et al. Outcome evaluation of carotid stenting in high-risk patients with symptomatic carotid near occlusion. Interv Neuroradiol 2010;16:309-16.

28. González A, Gil-Peralta A, Mayol A, et al. Internal carotid artery stenting in patients with near occlusion: 30day and long-term outcome. AJNR Am J Neuroradiol 2011;32:252-8.

29. Nikas DN, Ghany MA, Stabile E, et al. Carotid artery stenting with proximal cerebral protection for patients with angiographic appearance of string sign. JACC Cardiovasc Interv 2010;3:298-304.

30. Oka F, Ishihara H, Kato S, et al. Cerebral hemodynamic benefits after carotid artery stenting in patients with near occlusion. J Vasc Surg 2013;58:1512-7.

31. Razuk A, Caffaro R, Karakahanian W, et al. Carotid String Sign: Is There a Role for Carotid Stenting? 38th Annual Symposium of Society for Clinical Vascular Surgery Arizona, USA, 2010.

32. Ruiz-Salmerón RJ, Gamero MA, Carrascosa C, et al. Carotid artery stenting: clinical and procedural implications for near-occlusion stenosis. Neurologia 2013;28:535-42.

33. Sakamoto S, Kiura Y, Kajihara Y, et al. Carotid artery stenting using the proximal or dual protection method for near occlusion of the cervical internal carotid artery. Neurosurg Rev 2013;36:551-7; discussion 557-8.

34. Son S, Choi DS, Kim SK, et al. Carotid artery stenting in patients with near occlusion: a single-center experience and comparison with recent studies. Clin Neurol Neurosurg 2013;115:1976-81.

35. Spacek M, Martinkovicova L, Zimolova P, et al. Midterm outcomes of carotid artery stenting in patients with angiographic string sign. Catheter Cardiovasc Interv 2012;79:174-9.

36. Terada T, Tsuura M, Matsumoto H, et al. Endovascular treatment for pseudo-occlusion of the internal carotid artery. Neurosurgery 2006;59:301-9; discussion 301-9.

37. Ascher E, Markevich N, Hingorani A, et al. Pseudoocclusions of the internal carotid artery: a rationale for 
treatment on the basis of a modified carotid duplex scan protocol. J Vasc Surg 2002;35:340-5.

38. Bowman JN, Olin JW, Teodorescu VJ, et al. Carotid artery pseudo-occlusion: does end-diastolic velocity suggest need for treatment? Vasc Endovascular Surg 2009;43:374-8.

39. Fox AJ, Eliasziw M, Rothwell PM, et al. Identification, prognosis, and management of patients with carotid artery near occlusion. AJNR Am J Neuroradiol 2005;26:2086-94.

40. O'Leary DH, Mattle H, Potter JE. Atheromatous pseudo-occlusion of the internal carotid artery. Stroke 1989;20:1168-73.

41. Radak DJ, Tanaskovic S, Ilijevski NS, et al. Eversion carotid endarterectomy versus best medical treatment in symptomatic patients with near total internal carotid occlusion: a prospective nonrandomized trial. Ann Vasc Surg 2010;24:185-9.

42. Kim J, Male S, Damania D, et al. Comparison of Carotid Endarterectomy and Stenting for Symptomatic Internal Carotid Artery Near-Occlusion. AJNR Am J Neuroradiol 2019;40:1207-12.

43. Yan D, Tang X, Shi Z, et al. Perioperative and Followup Results of Carotid Artery Stenting and Carotid Endarterectomy in Patients with Carotid Near-Occlusion. Ann Vasc Surg 2019;59:21-7.

44. García-Pastor A, Gil-Núñez A, Ramírez-Moreno JM, et al. Early risk of recurrent stroke in patients with symptomatic carotid near-occlusion: Results from CAOS, a multicenter registry study. Int J Stroke 2017;12:713-9.

45. Lippman HH, Sundt TM Jr, Holman CB. The

Cite this article as: Antonopoulos CN, Giosdekos A, Mylonas SN, Liapis CD. Management of internal carotid artery near-occlusion: the need for updated evidence. Ann Transl Med 2020;8(19):1263. doi: 10.21037/atm.2020.03.148 poststenotic carotid slim sign: spurious internal carotid hypolasia. Mayo Clin Proc 1970;45:762-7.

46. Johansson E, Fox AJ. Carotid Near-Occlusion: A Comprehensive Review, Part 1--Definition, Terminology, and Diagnosis. AJNR Am J Neuroradiol 2016;37:2-10.

47. Ricotta JJ, Aburahma A, Ascher E, et al. Updated Society for Vascular Surgery guidelines for management of extracranial carotid disease. J Vasc Surg 2011;54:e1-31.

48. Abbott AL. Medical (nonsurgical) intervention alone is now best for prevention of stroke associated with asymptomatic severe carotid stenosis: results of a systematic review and analysis. Stroke 2009;40:e573-83.

49. Abbott AL, Brunser AM, Giannoukas A, et al. Misconceptions regarding the adequacy of best medical intervention alone for asymptomatic carotid stenosis. J Vasc Surg 2020;71:257-69.

50. Paraskevas KI, Veith FJ, Ricco JB. Best medical treatment alone may not be adequate for all patients with asymptomatic carotid artery stenosis. J Vasc Surg 2018;68:572-5.

51. Xue S, Tang X, Zhao G, et al. A Systematic Review and Updated Meta-analysis for Carotid Near-Occlusion. Ann Vasc Surg 2020;66:636-645.e3.

52. Smout J, Macdonald S, Weir G, et al. Carotid artery stenting: relationship between experience and complication rate. Int J Stroke 2010;5:477-82.

53. Johansson E, Ohman K, Wester P. Symptomatic carotid near-occlusion with full collapse might cause a very high risk of stroke. J Intern Med 2015;277:615-23. 